\title{
Gestão sustentável de resíduos sólidos em propriedades rurais do interior do RS
}

O presente estudo teve por intuito elucidar a situação das propriedades rurais de municípios do interior do Estado do Rio Grande do Sul, mas especificadamente da região do Médio Alto Uruguai, quanto à gestão dos resíduos. Verificar qual o nível de conhecimento quanto aos efeitos do descarte dos resíduos e a conscientização dos donos de propriedades rurais é o prelúdio de ações que possam contribuir para uma gestão rural mais sustentável e que possa ser, além de lucrativa, não nociva ao meio ambiente. A partir da abordagem qualitativa com metodologia exploratória e descritiva, os resultados coletados por meio da pesquisa de levantamento elucidaram que os proprietários admitem que o descarte dos resíduos muitas vezes é realizado de maneira incorreta, o que pode ser justificado pela falta de conhecimento específico dos malefícios desses atos para o meio ambiente e para própria saúde dos que habitam a propriedade e imediações. Seria interessante que houvesse palestras dos sindicatos e órgãos relativos a esses produtores referente a conscientização da importância do descarte dos resíduos nas propriedades rurais, pois muitos afirmam que existe falta de conhecimento e conscientização referente ao assunto. Ações no gerenciamento de resíduos do meio rural são necessárias para que a sustentabilidade aconteça. O prolongamento dos recursos naturais é responsabilidade de todos os âmbitos sociais, pois favorece o desenvolvimento. Portanto, conclui-se que, ainda, algumas pessoas agem de maneira incorreta no descarte de resíduos sólidos em propriedades rurais por falta de direcionamento, o que conduz o pensamento de que a educação sustentável e a percepção de busca da preservação do meio ambiente ainda são a melhor solução para mudar esse atual contexto.

Palavras-chave: Resíduos Sólidos; Sustentabilidade; Propriedades Rurais.

\section{Sustainable management of solid waste in rural properties of the interior of $R S$}

\begin{abstract}
The present study aimed to elucidate the situation of the rural properties of municipalities in the interior of the State of Rio Grande do Sul, but specifically in the region of Middle Uruguay, regarding the management of waste. To verify the level of knowledge regarding the effects of waste disposal and the awareness of the owners of rural properties is the prelude of actions that can contribute to a more sustainable rural management that can be not only profitable but not harmful to the environment. From the qualitative approach with exploratory and descriptive methodology, the results collected through the survey elucidated that the owners admit that the waste disposal is often carried out incorrectly, which can be justified by the lack of specific knowledge of the damages of these acts to the environment and to the health of those who inhabit the property and surroundings. It would be interesting if there were lectures by the trade unions and agencies related to these producers regarding awareness of the importance of waste disposal in rural properties, as many claim that there is a lack of knowledge and awareness about the subject. Actions in rural waste management are necessary for sustainability to happen. The extension of natural resources is the responsibility of all social spheres, as it favors development. Therefore, it is concluded that, still, some people act incorrectly in the disposal of solid waste on rural properties due to lack of direction, which leads to the idea that sustainable education and the perception of the search for preservation of the environment are still the best solution to change this current context.
\end{abstract}

Keywords: Solid Waste; Sustainability; Rural Properties.

Topic: Desenvolvimento, Sustentabilidade e Meio Ambiente

Reviewed anonymously in the process of blind peer.

Josiele Maria Fão (iD)

Universidade Regional do Noroeste do Estado do Rio Grande do Sul, Brasil http://lattes.cnpq.br/9347971113624616

http://orcid.org/0000-0001-8827-4716

josielefao@gmail.com

\section{Romualdo Kohler (iD)}

Universidade Regional do Noroeste do Estado do Rio Grande do Sul, Brasil http://lattes.cnpq.br/6303647678371344

http://orcid.org/0000-0003-2083-9279

romualdo@unijui.edu.br

Felipe Cavalheiro Zaluski (D)

Universidade Regional do Noroeste do Estado do Rio Grande do Sul, Brasil http://lattes.cnpq.br/5563360256401044

http://orcid.org/0000-0003-0942-9180

felipezaluski@hotmail.com

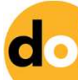

DOI: 10.6008/CBPC2179-6858.2018.005.0018
Received: 10/06/2018

Approved: 24/07/2018

Tarcisio Dorn de Oliveira

Universidade Regional do Noroeste do Estado do Rio Grande do Sul, Brasil http://lattes.cnpq.br/1493478586678556

http://orcid.org/0000-0001-5842-2415

tarcisio.oliveira@unijui.edu.br

Nelson José Thesing (iD

Universidade Regional do Noroeste do Estado do Rio Grande do Sul, Brasil http://lattes.cnpq.br/1975094711329644

http://orcid.org/0000-0001-7123-0717

nelson.thesing@unijui.edu.br

Referencing this:

FÃO, J. M.; KOHLER, R.; ZALUSKI, F. C.; OLIVEIRA, T. D.; THESING, N. J.. Gestão sustentável de resíduos sólidos em propriedades rurais do interior do RS. Revista Ibero Americana de Ciências Ambientais, v.9, n.5, p.196-208, 2018. DOI: http://doi.org/10.6008/CBPC21796858.2018.005.0018 


\section{INTRODUÇÃO}

Atualmente, a multinacionalização demanda que os recursos naturais sejam geridos e pensados em prol das gerações futuras. De fato, a sociedade repara com atenção as questões ambientais, além de estar atenta são necessárias ações por parte das pessoas e das organizações. Assim, a produção de lixo é considerada uma questão socioambiental, faz parte do saneamento básico junto com o tratamento da água e do esgoto e tem ressonância sobre a preservação dos recursos naturais.

Sob outra ótica, pode ser dito que o lixo, atualmente, é um dos grandes inconvenientes a serem enfrentados, fator que somado a falta de orientações e conscientização de parte da população para a gestão do lixo produzido, aumentam o problema exponencialmente. De modo geral, segundo Cabana et al. (2009), a produção de lixo no mundo é subdividida em três categorias: lixo reciclável (30\%), lixo degradável (50\%) e os $20 \%$ restantes, obrigatoriamente, devem ser depositados em locais previamente escolhidos para construção de aterros sanitários, de acordo com a legislação ambiental vigente em cada país.

No meio rural, o costume de descartar o lixo na margem dos rios, nos quintais das suas casas, enterrálo ou incinerá-lo é uma prática comum e constante. $O$ trabalho de coleta do lixo na área rural e em outros locais afastados dos grandes centros urbanos ainda é insuficiente, além do custo elevado, há impedimentos quanto ao acesso para a coleta nestes locais (RIBEIRO et al., 2010).

Pode ser citado como outro dilema nas propriedades rurais a destinação dos resíduos sólidos sejam eles, resíduos domésticos, ferrosos e de lixo proveniente de matérias de embalagens de agrotóxicos (lixo químico). Esta falta de preocupação com o destino correto dos resíduos está atrelada diretamente a saúde e a conservação do meio ambiente. É constatado desse modo, a dificuldade em destinar adequadamente o lixo que se produz em uma propriedade rural e destiná-lo da forma correta para uma melhor preservação do meio ambiente, assim como uma melhor condição de vida a quem mora na propriedade.

Os novos hábitos de consumo da sociedade acabaram trazendo também ao meio rural o lixo inorgânico, como plástico, metais e vidros, de uma forma volumosa. Essas espécies de lixo, se descartados incorretamente, levam anos para serem decompostos e em muitos casos geram contaminação do meio. Apesar de alguns moradores nas propriedades rurais manifestarem preocupação com questões ambientais, a conscientização ainda é escassa.

A geração de lixo sólido em propriedades rurais apresenta-se como um dos maiores problemas que se enfrenta na zona rural, visto que a destinação inadequada dos mesmos gera graves problemas ambientais nos mananciais, provocando rigorosa cobranças dos órgãos ambientais, pois na zona urbana existe a coleta do poder Público, o que não ocorre no interior. Já o lixo rural se torna inviável economicamente coletar e levar até as cidades onde estão os lixões ou aterros sanitários.

A sociedade precisa conscientizar-se que as facilidades que surgiram com a inovação e desenvolvimento, que proporcionaram acesso a bens de consumo que simplificam a vida, trazendo maior conforto são os mesmos que se descartados de maneira incorreta podem destruir o meio ambiente que é vital a existência humana. A comodidade de uma geladeira, por exemplo, é proporcional ao impacto 
ambiental gerado pelos elementos que a compõem se a mesma for descartada na beira de uma estrada ou na margem de um rio. Pode-se dizer que os hábitos da sociedade estão diretamente ligados a preservação do ambiente e garantia de seu desenvolvimento sustentável.

Para gerir os resíduos, geralmente são propostas estratégias que vão ao encontro no descarte, no entanto, talvez fosse mais eficaz focar na produção e no reaproveitamento desses resíduos. Dessa maneira, utilizar os recursos naturais de maneira mais coerente, evitando o desperdício tanto de matéria prima como de insumos, pode contribuir para tornar as propriedades rural mais sustentável, aumenta os lucros e reduz os custos.

Neste contexto, o presente estudo teve por intuito elucidar a situação das propriedades rurais de municípios do interior do Estado do Rio Grande do Sul, mas especificadamente da região do Médio Alto Uruguai, quanto à gestão dos resíduos. Verificar qual o nível de conhecimento quanto aos efeitos do descarte dos resíduos e a conscientização dos donos de propriedades rurais é o prelúdio de ações que possam contribuir para uma gestão rural mais sustentável e que possa ser, além de lucrativa, não nociva ao meio ambiente.

\section{REVISÃO TEÓRICA}

Nessa seção serão tratados de alguns conceitos relevantes para o estudo. Conceitos teóricos da gestão ambiental e da sustentabilidade, possibilitando uma compreensão mais ampla. Em seguida, de maneira mais sucinta, trata-se da gestão de resíduos sólidos e dos resíduos nas propriedades rurais. Desta forma, tem-se um embasamento conceitual teórico antes da exposição da abordagem dos resultados da pesquisa aplicada e suas considerações.

\section{Gestão sustentável}

Atualmente, a competitividade de maneira sustentável é evidenciada vigorosamente em várias empresas, pois a sustentabilidade apresenta uma relação direta com a produtividade e formas inovadoras de competir no mercado. A inovação além de introduzir novos produtos e processos no âmbito comercial auxilia na geração de menos impacto ambiental, deste modo os ganhos com produtividade reduzem o uso de recursos e acabam com o desperdício.

Sustentabilidade é um relacionamento entre sistemas econômicos em movimento e sistemas ecológicos maiores e também dinâmicos, embora de mudança mais lenta, em que a vida humana tem que continuar, os indivíduos podem progredir, as culturas humanas podem desenvolver-se, no entanto, os resultados das atividades humanas obedecem a limites para não destruir a diversidade, a complexidade e a função do sistema ecológico de apoio à vida (GALLO, 2007).

Desse modo, pode se dizer que a sustentabilidade engloba o crescimento das atividades humanas, com crescimento e inovação, mas que esse crescimento respeite os recursos naturais, de maneira a não afetar o sistema que garante o equilíbrio dos seres vivos, ou seja, o meio ambiente. É possível se desenvolver sem destruir os recursos naturais, utilizar sim, mas de maneira renovável. 
Conforme argumenta Almeida (2006), deve-se levar em consideração que o atual sistema de produção é administrado por incentivos econômicos e tem por norteador as exigências dos consumidores e a estrutura do mercado. A atual forma adotada pela sociedade de consumo e produção insustentáveis são um dos problemas mais graves que a humanidade enfrenta e que resultam em deterioração ambiental, aumento da pobreza e instabilidade no desenvolvimento da população.

$\mathrm{Na}$ atualidade, as empresas levam em conta a maneira de produzir, muitas já têm sua atenção não somente a fatores econômicos, mas também a questões ligadas a sustentabilidade, pois as leis e mobilizações sociais estão voltadas a essas ideias. Deste modo, as organizações estão se reestruturando e buscando reduzir os impactos ao meio ambiente, buscando assumir uma responsabilidade social.

Para Leff (2001), a sustentabilidade do desenvolvimento anuncia o limite da racionalidade econômica, proclamando os valores da vida, da justiça social e do compromisso com as gerações vindouras. A sustentabilidade surge como marco disciplinador que traz consigo medidas que garantem algumas limitações, garantindo alguns valores sociais e prerrogativas que possam proporcionar as gerações futuras qualidade de vida. Assim, para gerar a verdadeira sustentabilidade é necessária uma consciência ampla de que se trata de fatores multidisciplinares, que envolvem além do lado humano e ambiental, também o econômico. Toda empresa trabalha para gerar lucro, essa é sua finalidade, no entanto, nesse processo as ações podem ser direcionadas para que aconteça de maneira mais responsável, sem agredir o meio ambiente e gerando o mínimo de resíduos possível.

As empresas possuem atribuições indispensáveis no desenvolvimento sustentável da sociedade pois possui imensa capacidade de afetar os sistemas naturais e sociais. O setor empresarial se vê incontestavelmente envolvido na busca de um padrão de desenvolvimento diferenciado e inovador. Dessa maneira, o papel das organizações tem por intuito fazer parte de um processo contínuo, que começa na concepção do projeto e vai até a gestão desse negócio e todo esse sistema evolutivo deve seguir critérios do desenvolvimento sustentável.

Pode-se dizer que os desafios que os indivíduos e sociedade irão encarar futuramente são muitos, pois devem ser considerados elementos como as desigualdades econômicas, sociais e recursos ambientais. Algumas possibilidades para amenizar esta situação podem incluir: diminuir as diferenças de riquezas entre países e pessoas; desenvolver economias mais ricas e inclusivas e tecnologias inovadoras para energia, alimentação, transporte e moradias.

Como já citado anteriormente, a sustentabilidade é um multifacetado, abrange vários fatores distintos e remete-se a ela mudanças distintas que podem transformar a realidade da sociedade em vários aspectos. $\mathrm{O}$ conceito mais amplo de desenvolvimento sustentável se apoia na integração de ações sociais, ambientais e econômicas. Para Araújo (2006) e Dias (2006), uma empresa sustentável é aquela que contribui para o desenvolvimento sustentável ao gerar, simultaneamente, benefícios econômicos, sociais e ambientais, conhecidos como os três pilares do desenvolvimento sustentável, constituindo o tripé conhecido como Triple-Botton Line, apresentado na Figura 1 a seguir. 


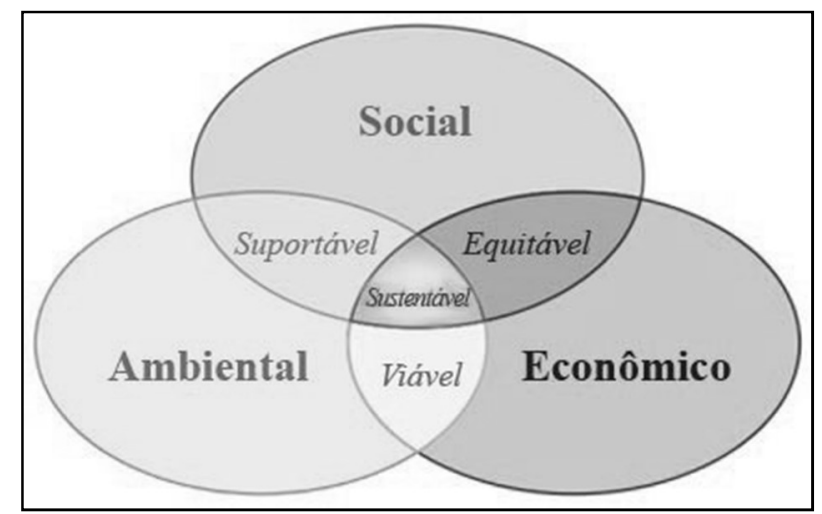

Figura 1: Tripé da sustentabilidade. Fonte: Almeida (2006).

Para que as organizações possam contribuir para a sustentabilidade, devem modificar seus processos produtivos, quando for necessário, para se tornarem sustentáveis. Isso implica construir sistemas de produção que não causem impactos negativos e que estejam contribuindo para a recuperação de áreas degradadas ou oferecendo produtos e serviços que contribuam para a melhoria da performance ambiental dos consumidores (CORAL, 2002).

O conceito do tripé da sustentabilidade (Triple-Bottom Line) tornou-se vastamente conhecido entre as empresas e os pesquisadores tornando-se assim um instrumento conceitual. As empresas que desejam ser sustentáveis têm a necessidade de ser tri-dimensionadas nos aspectos que abrangem o conceito. Para o setor empresarial, o conceito de sustentabilidade representa uma nova abordagem de fazer negócios que promove inclusão social, reduz e/ou otimiza o uso de recursos naturais e o impacto sobre o meio ambiente, sem desprezar a rentabilidade econômico-financeira da empresa. Tal abordagem cria valor para o acionista, promove maior probabilidade de continuidade do negócio e proporciona significativa contribuição a toda a sociedade (HOFFMAN, 2000).

Desenvolver de forma sustentável qualquer negócio é se certificar que este contribua para uma melhor qualidade de vida hoje proporcionando a mesma qualidade de vida das gerações futuras. Azapagic (2003) afirma que muitas empresas e organizações setoriais têm estado ativamente envolvidas na discussão da sustentabilidade, procurando meios para melhorar seu tripé e contribuir para o desenvolvimento sustentável.

Pode se afirmar ainda, que a sustentabilidade é vista como um fator estratégico no mercado. Fazer negócios no sentido de ser mais sustentável globalmente trouxe vantagens competitivas, além cumprir a legislação, proporcionou a várias organizações ser internacionalmente mais atraentes na hora de negociar. Na Conferência Mundial sobre Desenvolvimento Sustentável (World Business Council for Sustainable Development - WBCSD) em Johannesburgo, o relatório do Instituto Internacional do Desenvolvimento Sustentável identificou uma série de benefícios empresariais na abordagem do desenvolvimento sustentável (WBCSD, 2002): Redução de custos devido aos métodos de produção mais limpa e inovações: inovação e tecnologia podem aumentar a eficiência dos materiais, energia e do produto; Redução dos custos de saúde e segurança: um ambiente seguro e saudável para os trabalhadores e comunidade melhora o bem-estar, que se traduz em alta produtividade, reduz a compensação por danos, reduz os custos de serviços sociais e 
medicação; Redução dos custos salariais e soluções inovadoras: o fornecimento de boas condições de trabalho pode aumentar a motivação e a produtividade, reduzir os custos com absenteísmo ou rotatividade; Fácil acesso a instituições de crédito e seguros: baixo risco alcançado pela implementação de uma estratégia de desenvolvimento sustentável pode levar a menores taxas nos empréstimos e custos de seguros; Melhores práticas influenciam na regulamentação: empresas que seguem as melhores práticas são mais bem colocadas do que seus concorrentes e influenciam como as normas são definidas e a direção das alterações na regulamentação; Melhor reputação da empresa: o compromisso com o desenvolvimento sustentável pode melhorar a reputação e garantir a licença social para operar, além de ajudar a atrair as melhores pessoas para se juntar à empresa; Vantagem de mercado: o avanço da gestão integrada da cadeia de suprimentos pode permitir a construção de relacionamentos duradouros com clientes e captar mais valor pelo fornecimento de serviços em vez de somente vender produtos e; Investidores éticos: a rápida expansão da ética e do investimento socialmente responsável representa um novo desafio para as empresas na busca de investidores, principalmente aquelas com desempenho social e ambiental inaceitável.

Neste contexto, Knoepfel (2001) afirma que as organizações que utilizam a sustentabilidade alcançam suas metas de negócios por orientação de suas estratégias e devido à gestão de explorar o potencial de mercado de produtos e serviços sustentáveis, ao mesmo tempo que reduzem e evitam custos e riscos. É esta busca e a capacidade gerencial que criam, a longo prazo, o valor para a empresa e, consequentemente, para o acionista.

Diante disto, pode-se concluir que a sustentabilidade é uma ferramenta que quando adota gera vantagens indiretas e que seu grande diferencial pode ser percebido a longo prazo. Quem pensa sustentavelmente investe no futuro, não apenas de seu negócio, mas na qualidade de vida e melhorias sociais no mundo como um todo.

\section{Gestão de resíduos sólidos}

Atualmente pode ser observado que a maneira mais comum de agredir o meio ambiente é a geração de resíduos, pois cada vez mais a quantidade gerada seja na produção ou mesmo no descarte de embalagens industrializadas cresce. 0 modo de consumo globalizado contribuiu na redução das fronteiras para compra e venda, desse modo o que se produz na China e é comprado no Brasil, por exemplo, gera um fábrica de resíduos também sem fronteiras.

Ferreira (1986) define lixo como sendo aquilo que se varre da casa, do jardim, da rua e se joga fora e vira entulho. Ainda segundo o autor, é tudo o que não presta e se joga fora, sujeira, imundície, coisa inútil, velhas e sem valor. O que não pode ser reaproveitado. No entanto, resíduo é definido como sendo aquilo que resta de qualquer substância, ou seja, resto. Este pode ser reaproveitado. Desta maneira, pode-se observar que existe diferença até mesmo conceitual entre resíduo e lixo. O resíduo pode ser reutilizado, reciclado e transformado em outra matéria. Já o lixo só pode ser descartado, não tendo mais como ser transformado em outra matéria aproveitável. 
Lima (1995) afirma ainda que 'resíduo sólido' não se trata de uma definição simples pois provem de inúmeros fatores ligados à sua origem e formação. Os resíduos sólidos são materiais heterogêneos resultantes da atividade humana e da natureza, os quais podem ser parcialmente utilizados gerando proteção à saúde pública e economia de recursos naturais. Os resíduos sólidos causam problemas sanitários, ecológicos, econômicos e principalmente estéticos, o que acontece demasiadamente em propriedades rurais.

É de fundamental relevância que se conheça o tipo de lixo produzido e suas quantidades, pois isso serve de suporte para a definir como armazenar, coletar, transportar e descartar de maneira menos prejudicial ao ambiente. Quanto melhor a sociedade conhecer o lixo que produz, melhores serão as soluções de gestão e tratamento dos mesmos. Com este intuito, Fellenberg (1980) afirma que o conceito de poluição ambiental é muito abrangente e engloba desde a contaminação do solo, ar e água até a desfiguração de paisagens, erosão de monumentos, entre tantos outros exemplos. Sob a ótica de Bidone et al. (1999), a geração de resíduos está ligada a fatores de cultura, padrão de vida, hábitos de consumo e particularidades demográficas da população. A própria economia do país tem interferência na forma de produzir resíduos e é proporcional aos períodos de crescimento e recessão econômica, como acontece nas propriedades rurais.

Os resíduos são regulamentados pela NBR 10.004, essa norma classifica os resíduos pelos riscos potenciais ao meio ambiente. Existem cinco critérios que são levados em conta quanto a periculosidade: a) inflamabilidade; b) corrosividade; c) reatividade; d) toxidade e; e) patogenicidade (excluídos os resíduos sólidos domiciliares e aqueles gerados em estações de tratamento de esgotos sanitários).

$\mathrm{Na}$ falta de inclusão de um resíduo nos critérios citados a NBR criou mais três normas 10.005 (Lixiviação de resíduos - procedimentos), 10.006 (Solubilização de resíduos - procedimentos) e 10.007 (Amostragem de resíduos - procedimentos). O Quadro 1 a seguir apresenta as características e classes dos resíduos:

Quadro 1: Classificação dos resíduos sólidos.

\begin{tabular}{|c|c|}
\hline CATEGORIA & \\
\hline $\begin{array}{l}\text { Classe } \\
\text { (perigosos) }\end{array}$ & $\begin{array}{l}\text { São aqueles que, em função de suas características intrínsecas de inflamabilidade, corrosividade, reatividade, } \\
\text { toxicidade ou patogenicidade, apresentam riscos à saúde pública através do aumento da mortalidade ou da } \\
\text { morbidade, ou ainda provocam efeitos adversos ao meio ambiente quando manuseados ou dispostos de forma } \\
\text { inadequada. }\end{array}$ \\
\hline inertes) & $\begin{array}{l}\text { São os resíduos que podem apresentar características de combustibilidade, biodegradabilidade ou solubilidade, com } \\
\text { possibilidade de acarretar riscos à saúde ou ao meio ambiente, não se enquadrando nas classificações de resíduos } \\
\text { Classe I Perigosos }\end{array}$ \\
\hline $\begin{array}{l}\text { Classe } \\
\text { (inertes) }\end{array}$ & $\begin{array}{l}\text { São aqueles que, por suas características intrínsecas, não oferecem riscos à saúde e ao meio ambiente, e que, quando } \\
\text { amostrados de forma representativa, segundo a norma NBR } 10.007 \text {, e submetidos a um contato estático ou dinâmico } \\
\text { com água destilada ou deionizada, a temperatura ambiente, conforme teste de solubilização segundo a norma NBR } \\
\text { 10.006, não tiverem nenhum de seus constituintes solubilizados a concentrações superiores aos padrões de } \\
\text { potabilidade da água, conforme listagem n. } 8 \text { (Anexo H da NBR 10.004), excetuando-se os padrões de aspecto, cor, } \\
\text { turbidez e sabor. }\end{array}$ \\
\hline
\end{tabular}

Fonte: Associação Brasileira de Normas Técnicas (2004).

\section{Resíduos em propriedades rurais}

Os resíduos sólidos refletem a sociedade que os geram, e quando expostos nas vias públicas ou nas propriedades rurais, mostram o nível de consciência das pessoas. A coleta de lixo na área rural ainda é 
insuficiente, a realidade mostra que o lixo rural tem coleta cara e difícil o que leva os agricultores a optarem por enterrá-lo ou queimá-lo.

Os incineradores convencionais são fornos, nos quais se queimam os resíduos. Além de calor, a incineração gera dióxido de carbono, óxidos de enxofre e nitrogênio, dioxinas e outros contaminantes gasosos, cinzas voláteis e resíduos sólidos que não se queimam. É possível controlar a emissão de poluentes mediante processos adequados de limpeza dos gases (VALLE, 1996). O autor, ainda comenta que a reciclagem é outra forma de dar destino a resíduos, e essa prática é usada a bastante tempo também. Os utensílios metálicos são fundidos e remodelados desde os tempos pré-históricos. Os materiais recicláveis são recuperados de muitas maneiras, como o desfibramento, separação magnética de metais, separação de materiais leves e pesados, peneiração e lavagem.

Parafraseando Backer (1995), pode-se perceber que atualmente existe uma preocupação com o meio ambiente e sua degradação, pois o crescimento econômico também possui efeitos colaterais. E estes efeitos chegaram também às propriedades rurais, pois estas são indústrias do agronegócio. A atividade industrial, mesmo no agronegócio, não deve agredir o meio ambiente, mas desenvolver suas atividades em concordância com sua preservação e se não levado esses princípios em conta, o meio rural pode ser ainda mais danoso ao meio ambiente.

Deste modo Cabana et al. (2009) defendem que a educação ambiental é um novo conceito de educação voltada para a sustentabilidade da relação entre sociedade e natureza. De fronte aos problemas ambientais que podem ser analisados e solucionados a partir de mudanças nos processos de aprendizagem e propagação de conhecimentos. Segundo o Conselho Nacional do Meio Ambiente (CONAMA), Educação Ambiental é um processo de formação e informação orientada para o desenvolvimento da consciência crítica sobre as questões ambientais, e de atividades que levem à participação das comunidades na preservação do equilíbrio ambiental. Conservar a natureza e melhorar a qualidade de vida tem sido uma preocupação da sociedade há algum tempo. Com isto, intensifica-se a demanda por atividades que estimulem o desenvolvimento de uma consciência ambiental que vise às questões sociais, culturais e econômicas relacionadas a sociedade.

\section{METODOLOGIA}

Para atingir o objetivo proposto por esse projeto, foi realizada uma abordagem qualitativa. 0 presente trabalho está baseado em uma pesquisa exploratória e descritiva, com levantamento a campo. Exploratória, porque segundo Lakatos et al. (2006), visa aumentar a familiaridade do pesquisador com o ambiente, fato ou fenômeno. Descritiva em virtude de descrever características quantitativas de uma determinada população, que no caso tratam-se dos moradores das propriedades rurais.

A coleta de dados foi realizada durante uma feira multissetorial realizada na cidade de Frederico Westphalen, localizado no Estado do Rio Grande do Sul, onde ocorreu encontro voltado a agricultores da região do médio alto Uruguai. Na oportunidade foram entrevistados 47 agricultores, com um questionário com perguntas fechadas e abertas. Após a aplicação dos questionários, os dados foram tabulados 
estatisticamente com a elaboração de gráficos, os quais permitiram análise e interpretação mais direta, pois foi reduzida a sua complexidade, conforme mencionado por Lakatos et al. (1992).

\section{RESULTADOS E DISCUSSÃO}

Após a aplicação de questionário e tabulação dos dados, forma construídas algumas tabelas que elucidam os dados do estudo. A Tabela 1 a seguir apresenta a análise do perfil dos entrevistados.

Tabela1: Perfil dos entrevistados.

\begin{tabular}{|l|l|l|}
\hline ITEM & DESCRIÇÃO & $\%$ \\
\hline Faixa etária & 20 a 30 anos & $47,9 \%$ \\
\cline { 3 - 3 } & 40 a 60 anos & $52,1 \%$ \\
\hline Grau de instrução & 1o grau completo & $41,8 \%$ \\
\cline { 2 - 3 } & 2 o grau completo & $31,2 \%$ \\
\cline { 2 - 3 } & Ensino superior & $27 \%$ \\
\hline
\end{tabular}

O perfil dos entrevistados durante a pesquisa foi definido como $47,9 \%$ na faixa etária entre 20 a 30 anos e $52,1 \%$ na faixa entre 40 a 60 anos, o que demonstra que muitos jovens optaram por atuar no meio rural nessa região e que a população mais velha ainda sobrevive da economia agrícola, fortalecendo o agronegócio regional. 0 grau de instrução que mais ficou evidenciado foi o de 19 grau incompleto, com $41,8 \%$, podendo ser justificado pela quantidade de pessoas mais velhas que enfrentavam dificuldades em estudar em épocas passadas, porém um percentual de $31,2 \%$ de pessoas possui 2 o grau completo e $27 \%$ concluíram ensino superior, o perfil dos entrevistados apresenta dados que confirmam a tendência de uma contínua profissionalização do meio rural, o que muito tem a contribuir com o desenvolvimento da agricultura.

Tabela 2: Caracterização da propriedade.

\begin{tabular}{|l|l|l|}
\hline ITEM & DESCRIÇÃo & $\%$ \\
\hline Tamanho da propriedade & Até 20 hectares & $68,1 \%$ \\
& 20 a 80 hectares & $25,5 \%$ \\
& 80 a 300 hectares & $4,3 \%$ \\
& Acima de 300 hectares & $2,1 \%$ \\
\hline Faturamento anual & Até 30 mil reais & $55,3 \%$ \\
& 30 a 50 mil reais & $25,00 \%$ \\
\hline Localização & 200 a 280 mil reais & $19,7 \%$ \\
& Frederico Westphalen & $63,5 \%$ \\
\hline Ocupação da propriedade & Vista Alegre & $23,5 \%$ \\
& Outros Municípios & $13 \%$ \\
\hline Funcionários & Agricultura e pecuária & $44,3 \%$ \\
& Agricultura & $38,3 \%$ \\
& Pecuária & $12,8 \%$ \\
\hline
\end{tabular}

Quando questionados em relação ao tamanho de propriedade, $68,1 \%$ tem até 20 hectares, característica de minifúndio, $25,5 \%$ possui de 20 a 80 hectares, característica de pequena propriedade, $4,3 \%$ de 80 a 300 hectares, característica de média propriedade e 2,1\% acima de 300 hectares, característica de grande propriedade. O faturamento anual das propriedades apresentou-se pela seguinte descrição, 55,3\% 
até 30 mil reais, $25 \%$ de 30 a 50 mil reais e $19,7 \%$ de 200 a 280 mil reais, o que caracteriza a maioria dos entrevistados como pequenos produtores rurais.

Quanto a localização a maioria das propriedades, 63,5\% estão localizadas no município de Frederico Westphalen, 23,5\% em Vista Alegre, 13\% em outros municípios próximos como Tenente Portela, Ametista do Sul, Caiçara, Lajeado do Bugre, Taquaruçu do Sul, Rodeio Bonito, Erval Seco, Novo Tiradentes, Palmeira das Missões, Jabuticaba e Palmitinho. A principal ocupação na propriedade foi identificada como sendo a agricultura e pecuária com $44,3 \%$ dos respondentes, seguida pela agricultura com 38,3\%, pela pecuária com 12,8\% e a pouco expressiva agroindústria com 4,6\%, o que evidencia características de agricultura familiar como apresenta os dados que demonstram que $89,4 \%$ afirmam que não possuem funcionários pois é uma propriedade familiar e apenas 10,6\% afirmam possuir até 5 funcionários na propriedade.

Tabela 3: Análise da gestão ambiental.

\begin{tabular}{|c|c|c|}
\hline ITEM & DESCRIÇÃO & $\%$ \\
\hline \multirow[t]{2}{*}{ Preocupação com o meio ambiente } & \multirow{2}{*}{$\begin{array}{l}\text { Grande preocupação e realização de ações que não } \\
\text { afetam o meio ambiente } \\
\text { Preocupação parcial e as ações desenvolvidas não } \\
\text { afetam o meio ambiente }\end{array}$} & $55,3 \%$ \\
\hline & & $44,7 \%$ \\
\hline $\begin{array}{l}\text { Questões ambientais (poluição e desmatamento) afetam o } \\
\text { cotidiano }\end{array}$ & $\begin{array}{l}\text { Sim, é uma das maiores preocupações } \\
\text { Afeta, mas é em menor importância } \\
\text { Não faz parte das preocupações diárias }\end{array}$ & $\begin{array}{l}53,5 \% \\
31,6 \% \\
14,9 \%\end{array}$ \\
\hline A importância da coleta de resíduos em sua propriedade & $\begin{array}{l}\text { Muito importante } \\
\text { Extremamente importante } \\
\text { Importante } \\
\text { Pouco importante } \\
\text { Nenhuma importância }\end{array}$ & $\begin{array}{l}36,2 \% \\
27,6 \% \\
25,5 \% \\
6,4 \% \\
4,3 \%\end{array}$ \\
\hline Existência de coleta de resíduos na propriedade & $\begin{array}{l}\text { Realizada coleta seletiva } \\
\text { Não é realizada }\end{array}$ & $\begin{array}{l}61,7 \% \\
38,3 \% \\
\end{array}$ \\
\hline Destino de resíduos não coletados & $\begin{array}{l}\text { Incineram } \\
\text { Enterram } \\
\text { Lixão público } \\
\text { Reutilizam } \\
\text { Jogam a céu aberto } \\
\end{array}$ & $\begin{array}{l}46,8 \% \\
21,3 \% \\
19,2 \% \\
10,6 \% \\
2,1 \% \\
\end{array}$ \\
\hline $\begin{array}{l}\text { Tiveram recomendações de órgão de fiscalização para } \\
\text { controle de resíduos }\end{array}$ & $\begin{array}{l}\text { Nunca } \\
\text { Sim } \\
\text { Parcialmente }\end{array}$ & $\begin{array}{l}57,5 \% \\
28,5 \% \\
14 \%\end{array}$ \\
\hline $\begin{array}{l}\text { Empresas fornecedoras recomendam procedimento quanto } \\
\text { ao descarte dos resíduos }\end{array}$ & $\begin{array}{l}\text { Não orientam } \\
\text { Orientam parcialmente } \\
\text { Orientam }\end{array}$ & $\begin{array}{l}27,7 \% \\
27,7 \% \\
44,6 \%\end{array}$ \\
\hline $\begin{array}{l}\text { Conscientização e orientação de funcionários e colaboradores } \\
\text { da propriedade }\end{array}$ & $\begin{array}{l}\text { Conscientes e sabem da importância } \\
\text { Falta incentivo } \\
\text { Falta orientação e divulgação }\end{array}$ & $\begin{array}{l}45,2 \% \\
34,8 \% \\
20 \%\end{array}$ \\
\hline Inspeção ou vistor de órgãos na propriedade & $\begin{array}{l}\text { Nenhum órgão } \\
\text { PROMOTORIA } \\
\text { FEPAM } \\
\text { CONAMA }\end{array}$ & $\begin{array}{l}70,2 \% \\
23,4 \% \\
4,3 \% \\
2,1 \%\end{array}$ \\
\hline $\begin{array}{l}\text { Avaliação de iniciativas da propriedade para controle de } \\
\text { resíduos e sustentabilidade }\end{array}$ & $\begin{array}{l}\text { Propriedade está parcialmente adequada } \\
\text { Adequada } \\
\text { Inadequada e não realiza prevenção de maneira correta } \\
\text { Inadequada mas pretende implantar iniciativas }\end{array}$ & $\begin{array}{l}46,8 \% \\
38,3 \% \\
8,5 \% \\
6,4 \%\end{array}$ \\
\hline
\end{tabular}

Quando questionados a respeito da existência de preocupação com o meio ambiente, 55,3\% afirmaram que há grande preocupação e que estão sendo realizadas ações que não afetem o meio ambiente, 44,7\% admitem que a preocupação é parcial, mas que as atividades desenvolvidas não afetam o meio 
ambiente, essas respostas demonstram que o produtor rural não está alheio as preocupações ambientais que são difundidas e cobradas em lei atualmente.

Quanto as questões ambientais como a poluição e desmatamento afetam o seu cotidiano, 53,5\% responderam que sim e é uma das maiores preocupações, enquanto 31,6\% dizem que afeta, mas é uma preocupação secundária de menor importância e 14,9\% acredita que não faz parte das suas preocupações diárias, o que mesmo sendo uma pequena porcentagem, demonstra a falta de conhecimento sobre o que engloba as questões ambientais na agricultura.

Referente a coleta de resíduos nas propriedades, questionou-se a percepção do agricultor a respeito à sua importância, 36,2\% acredita ser muito importante, $27,6 \%$ responderam que é extremamente importante, $25,5 \%$ respondeu que é importante, $6,4 \%$ que é pouco importante e apenas $4,3 \%$ respondeu que não tem nenhuma importância, ou seja, a maioria dos agricultores sabe da importância do gerenciamento desses resíduos. Foi questionado ainda referente a realização de coleta de resíduos na propriedade, se é realizada, $61,7 \%$ afirmaram que é realizada a coleta seletiva e 38,3\% diz que não é realizada.

Quanto ao destino dos resíduos que não são coletados, foi identificada a seguinte situação: 46,8\% incineram, 21,3\% enterram, 19,2\% levam para o lixão público, 10,6\% reutilizam e 2,1\% jogam a céu aberto. Diante disso, questionou-se se a propriedade já teve recomendações ou exigências de algum órgão de fiscalização municipal, estadual ou privado a respeito do controle de resíduos sólidos, 57,5\% responderam que nunca, $28,5 \%$ que sim e $14 \%$ que parcialmente.

Outra questão foi se as empresas que fornecem produtos e insumos recomendam ou exigem destino aos resíduos, 27,7\% disseram que não orientam, 27,7\% que orientam parcialmente dos perigos para o meio ambiente e $44,6 \%$ que são orientados para que haja o retorno dos resíduos para a empresa. Quanto a conscientização e orientação de funcionários e colaboradores da propriedade a respeito da destinação dos resíduos, 45,2\% dizem que os mesmos estão conscientes e sabem da importância, 34,8\% admitem que falta incentivá-los e $20 \%$ que falta orientação e divulgação.

Quando questionados se a propriedades já recebeu algum tipo de inspeção ou vistoria de órgãos, federal CONAMA, estadual FEPAM, municipal PROMOTORIA, ou outro, 70,2\% afirmaram que nenhuma desses órgãos fez vistoria em suas propriedades, 23,4\% já receberam a PROMOTORIA, 4,3\% a FEPAM e apenas 2,1\% receberam a CONAMA. Questionados referente a avaliação das iniciativas da propriedade para o controle de resíduos e a sustentabilidade, $46,8 \%$ afirmaram que a propriedade está parcialmente adequada e que começou a realizar recentemente a destinação, 38,3\% afirmou que realiza os procedimentos de maneira adequada, 8,5\% admitiu que a propriedade está inadequada e que não está realizando a prevenção de maneira correta e 6,4\% que está inadequada, mas que pretende implantar com urgência algumas iniciativas nesse sentido.

\section{CONCLUSÕES}

Partindo das informações elucidadas e analisadas no estudo, pode-se perceber que a maioria dos produtores rurais está, aos poucos, tomando consciência da importância de desenvolver a agricultura 
atrelada a responsabilidade ambiental. Isso é de grande valor para que se construa uma agricultura sustentável, aumentando a produtividade e reduzindo o impacto aos recursos naturais.

A amostra entrevistada é na sua grande maioria parte da agricultura familiar, característica da Região do Alto Uruguai do Estado do Rio Grande do Sul. Os mesmos admitem que o descarte dos resíduos muitas vezes é realizado de maneira incorreta, o que pode ser justificado pela falta de conhecimento específico dos malefícios desses atos para o meio ambiente e para própria saúde dos que habitam a propriedade e imediações. Seria interessante que houvesse palestras dos sindicatos e órgãos relativos a esses produtores referente a conscientização da importância do descarte dos resíduos nas propriedades rurais, pois muitos afirmam que existe falta de conhecimento e conscientização referente ao assunto.

Existe ainda uma necessidade de maior orientação das empresas fornecedoras de insumos, sementes e agrotóxicos, com devida aplicação de uma logística reversa das embalagens. Outro ponto observado, partindo das respostas dos entrevistados, foi a necessidade de uma maior atenção dos órgãos responsáveis por inspeções e vistorias, pois é alarmante o número de propriedades que nunca receberam uma visita, deixando de fato a fiscalização obsoleta nesse meio.

Ações no gerenciamento de resíduos do meio rural são necessárias para que a sustentabilidade aconteça. O prolongamento dos recursos naturais é responsabilidade de todos os âmbitos sociais, pois favorece o desenvolvimento. Portanto, conclui-se que, ainda, algumas pessoas agem de maneira incorreta no descarte de resíduos sólidos em propriedades rurais por falta de direcionamento, o que conduz o pensamento de que a educação sustentável e a percepção de busca da preservação do meio ambiente ainda são a melhor solução para mudar esse atual contexto.

\section{REFERÊNCIAS}

ALMEIDA, F.. O bom negócio da sustentabilidade. Rio de Janeiro: Nova Fronteira, 2006

ARAÚJO, G. C.; MORAIS, W. A. C.; MENDONÇA, P. S. M. M.. O processo de adequação às normas internacionalmente reconhecidas em relação à sustentabilidade. In: SIMPÓSIO DE ADMINISTRAÇÃO DA PRODUÇÃO, LOGÍSTICA E OPERAÇÕES INTERNACIONAIS, 9. Anais. São Paulo: FGVEaesp, 2006.

ABNT. Associação Brasileira de Normas Técnicas. NBR 10.004: Resíduos sólidos: classificação. Rio de Janeiro, 2004.

AZAPAGIC, A.. Systems Approach to Corporate Sustainability: A General Management Framework. Process Safety and Environmental Protection, v.81, n.5, p.303-315, 2003.

BACKER, P.. Gestão Ambiental: A Administração verde. Tradução de Heloísa Martins Costa, Rio de Janeiro: Qualitymark, 1995.

BIDONE, F. R. A.; TEIXEIRA, E. N.. Metodologia e técnicas de minimização, reciclagem e reutilização de resíduos sólidos urbanos. Rio de Janeiro: ABES, 1999.
CABANA, G. S.; COSTA, A. J. V.; SOUZA, D. S.. A Educação Ambiental como Instrumento para Gestão do Lixo no Espaço Rural. Pelotas: UFPEL, 2009.

CORAL, E.. Modelo de planejamento estratégico para a sustentabilidade empresarial. Tese (Doutorado em Engenharia da Produção) - Universidade Federal de Santa Catarina, Florianópolis, 2002.

DIAS, R.. Gestão Ambiental: Responsabilidade Social e Sustentabilidade. São Paulo: Atlas, 2006.

FELLENBERG, G.. Introdução aos problemas da poluição ambiental. São Paulo: EPU, 1980.

FERREIRA, A. B. H.. Novo dicionário da língua portuguesa. 2 ed. Rio de Janeiro: Nova Fronteira, 1986.

GALLO, Z.. Ethos, a grande morada humana: economia, ecologia e ética. Itu: Ottoni, 2007.

HOFFMAN, A. J.. Environmental and social issues into corporate practice. Environment, v.42, n.5, p.22, 2000.

KNOEPFEL, I.. Dow Jones sustainability group index: a global benchmark for corporate sustainability. Corporate Environmental Strategy, v.8, p.6-15, 2001. 
LAKATOS E. M.; MARCONI M. A.. Fundamentos de metodologia científica. 4 ed. 1992.

LAKATOS, E. M.; MARCONI, M. A.. Metodologia científica. 4 ed. São Paulo: Atlas, 2006.

LEFF, E.. Saber ambiental: sustentabilidade, racionalidade, complexidade, poder. Petrópolis: Vozes, 2001.

LIMA, L. M. Q.. Lixo: tratamento e biorremediação. 3 ed., São Paulo: Hemus, 1995.
RIBEIRO, F. S.. Os Possíveis Impactos Ambientais Causados pelo Aumento do Lixo Rural. São Paulo: USP, 2010.

VALLE, C. E.. Como se preparar para as normas ISO 14000 (O desafio de ser competitivo protegendo o meio ambiente). 2 ed. São Paulo: Pioneira, 1996.

WBCSD. World Business Council For Sustainable Development. Eco-Efficiency: Creating more value with less impact. Geneva: WBCSD, 2002.

A CBPC - Companhia Brasileira de Produção Científica (CNPJ: 11.221.422/0001-03) detém os direitos materiais desta publicação. Os direitos referem-se à publicação do trabalho em qualquer parte do mundo, incluindo os direitos às renovações, expansões e disseminações da contribuição, bem como outros direitos subsidiários. Todos os trabalhos publicados eletronicamente poderão posteriormente ser publicados em coletâneas impressas sob coordenação da Sustenere Publishing, da Companhia Brasileira de Produção Científica e seus parceiros autorizados. Os (as) autores (as) preservam os direitos autorais, mas não têm permissão para a publicação da contribuição em outro meio, impresso ou digital, em português ou em tradução. 